\title{
Prevalence of Repetitive Strain Injuries in Upper Extremities Among Egyptian School Teachers: A Cross Sectional Study
}

\author{
MOHAMMED H. EL GENDY, Ph.D.; NABIL M. ABDEL-AAL, Ph.D. and MARIAM YACOUP ATTIA, M.Sc. \\ The Department of Physical Therapy for Basic Sciences, Faculty of Physical Therapy, Cairo University
}

\begin{abstract}
Background: The prevalence of Repetitive strain injuries (RSIs) in upper extremities is reported in many countries, but its occurrence among teachers in Egypt has not been reported.

Aim of Study: To investigate the prevalence of RSIs in teachers at Giza Schools and to assess the effect of RSIs on the hand and pinch grip strengths.

Material and Methods: A sample of 515 teachers has been recruited from secondary schools in Giza. Subjects had 5 or more years of work experience and their age ranged from 35 to 60 years old. Participants were asked to answer the selfstructured questionnaire. Hand and pinch grip strengths were measured by hand grip and pinch grip dynamometers.

Results: The prevalence of RSIs in Giza school teachers was $89.51 \%$. There was an impact of RSIs on the hand and pinch grip strength. Hand grip strength or pinch grip strength was the highest affected component $(86.55 \%)$. There was a significant increase in the prevalence of RSIs in the right upper limb $86.6 \%$ compared with that the left upper limb $13.4 \%$. The prevalence of RSIs was greater with exceeding many hours per week, elongated manners during schooling, ageing, and among females.

Conclusion: There was a highly significant prevalence of RSIs in upper extremities among teachers in Giza schools $(p=0.0001)$. Also, there was a negative impact of RSIs on the hand and pinch grip strengths.
\end{abstract}

Key Words: Repetitive strain injuries - Prevalence - Teachers.

\section{Introduction}

MUSCULOSKELETAL disorders (MSDs) are frequent, with eighty percent of people experiencing neck pain at some point of their lives. The risk factors reported to MSDs comprise uneasy stance, extended posture, weighty lifting, and work atmosphere [1] . Repetitive strain injury (RSI) is one sort of MSD that affects the upper extremity and neck [2] . Repetitive strain injury was characterized as

Correspondence to: Dr. Mariam Yacoup Attia, E-Mail: mariam.yacoub93@ gmail.com injury induced or exacerbated by repeated or prolonged maximal exertion of the soft tissue constructions of the body, that include ligaments, tendons, muscles, and nerves. The prevalence of RSI is increased in the workplace which associated with substantial indirect costs to society [3].

Appreciation of teachers and their health is very important because their work is quite indispensable in any country. The future development of any nation is in the hands of teachers [4], but their work tasks often involve a significant use of a 'head down' posture and prolonged stressed position which cause a high prevalence of RSIs, with prevalence rates of $40 \%$ to $95 \%$, during the course of their work [5]. Several studies show that teachers have a higher incidence of RSIs than those in other occupations especially in the upper extremities that reach up to $95 \%[\mathbf{1 , 5 , 6 ]}$. The neck muscle spasm may produce a significant weakness of the intrinsic musculature of the hand [7], and the hand function especially hand pinch grip that has an impotent role for school teachers [8]

The prevalence of RSIs among teachers has been published in different countries; however, it has not been investigated among Egyptian teachers. Hence the aim of this study was to examine the prevalence of RSIs in upper extremities among

\footnotetext{
Abbreviations:

RSI : Repetitive strain injury.

MSDs : Musculoskeletal disorders.

$\mathrm{X}^{2} \quad$ : Chi squared value.

$p$-value : Probability value.

$\mathrm{x}$ : Mean.

SD : Standard deviation.

MD : Mean difference.

$t$-value : Unpaired $t$-value.

$p$-value : Probability value.

CI : Confidence interval.
} 
teachers in Giza schools, and to measure the impact of repetitive strain injuries on the hand and pinch grip strengths among teachers in Giza Schools.

\section{Material and Methods}

\section{Design and setting:}

This cross-sectional analytic research was carried out at different schools in Giza between November 2019 and December 2020. The current study was approved by the Faculty of Physical Therapy, Cairo University's ethical committee (P.T.REC/012/002528). All the participants had been knowledge able about the aim and advantages of the study and signed the written consent form before participation.

\section{Subjects:}

A sample of 515 teachers from both genders participated in the study.

The inclusion criteria included:

- Age between 35 to 60 years old.

- Five years or more of work experience.

- Pain experienced for more than three months prior to the study.

- The participant's conditions were confirmed by a positive structural questionnaire.

-Whereas healthy teachers have experienced no neck pain for three months prior to the study.

\section{The exclusion criteria included:}

- Osteoarthritis on hand.

- Other orthopedic conditions.

- Neurological conditions.

- Shoulder surgery.

- Upper limb fracture.

\section{Sample size and sampling methodology:}

The sample size of this research was estimated using a single population ratio formula calculator at http://sampsize.sourceforge.net/iface/\#prev by considering $50 \%$ prevalence of RSIs, $95 \%$ confidence period and 5\% margin of error (precision). So, the estimated sample size was 385 school teachers. Eventually, the sample size of 515 was obtained by adding $33 \%$ non-response rate.

As of November 2019, there were 121 governmental secondary schools in Giza governorate. Multi-stage sampling methodology was considered to select the research participants. Firstly, governmental secondary schools in Giza governorate were selected based on the area of location. Subsequently, twenty one schools were proportionally chosen using simple casual sampling from each stratify. From the selected schools the samples were proportionally recruited according to the total number of teachers in the chosen school using an alphabetical list.

\section{Questionnaires and measurements:}

- The self-structural questionnaire: The structural Questionnaire focused on the following three parts: Part one, Demographic characteristics include age, gender, education, marital status, number of children, part time jobs, number of working hours per week, and years of teaching experience. Part two, Health condition includes health attitude (drinking coffee, doing regular exercise, wearing high heel shoe), history of trauma, inherited and chronic diseases, osteoarthritis on hand, shoulder surgeries, upper extremity fractures, site of RSIs, right or left side of RSIs and the duration of pain. Part three, work characteristics includes teaching posture, and stretching to write on board [1]

- Hand grip dynamometer: JAMAR hand dynamometer (Lafayette Instrument Company, USA) was used to test the handgrip strength. It is the most commonly cited in the literature and accepted as the gold standard by which other dynamometers are assessed. It has the most widespread normative data [9]. The JAMAR is small and portable. The dial reads strength in kilograms and pounds, with marks at increases of $2 \mathrm{~kg}$ or $5 \mathrm{lb}$ [10]

- Pinch grip dynamometer: Is an instrument for measuring the maximum isometric strength of the thumb to index finger, pulp to pulp pinch grip. It is highly reliable and valid instrument for testing pinch grip strength. It is an ideal tool for measuring isometric tip, key and palmar pinch strength [9]. The innovative configuration of the JAMAR Hydraulic Pinch Gauge frees the client to execute a correct pinch pattern since the therapist, not the client, supports the load of the gauge. The result is a very precise pinch-force calculation, clear of artifact. The Red Indicator needle remains at full reading time until reset [11]

\section{Statistical analysis:}

Descriptive figures of mean, standard deviation, frequencies, percentages and confidence interval (CI) were utilized in presenting the subjects' demographic and clinical data. Quantitative variables were recapitulated using mean and standard deviation, while categorical variables were recapitulated using frequencies and percentage. The relationship between risk factors and RSIs was examined by chi-square test and logistic regression. Right and left hand and pinch grip strength were compared 
in subjects with right and left RSIs using paired $t$ test. The level of significance for all statistical tests was set at $p<0.05$. All statistical measures were carried out using the statistical package for social studies (SPSS) version 25 for windows.

\section{Results}

\section{I- Demographic characteristics:}

The age of the participants was $42.21 \pm 6.47$ years (min. 31 , max. 60 ), and $50.3 \%$ of subjects were less than 40 years old, while $49.7 \%$ were more than 40 years old. The teaching experience of the participants was $16.07 \pm 6.54$ years (min. 5, max. 38), and 258 (50.1\%) subjects had less than 16 years of teaching experience, while 257 (49.9\%) subjects had more than 16 years of teaching experience. One hundred seventy-seven teachers (34.4\%) were males, while $338(65.6 \%)$ were females. Two hundred eighty-eight (56\%) subjects worked more than $40 \mathrm{hr}$./week, and 227 (44\%) worked less than $40 \mathrm{hr}$./week.

\section{II- Health status:}

Twenty three $(4.5 \%)$ subjects had a chronic disease, twelve $(2.3 \%)$ subjects had a shoulder surgery, thirty one $(6 \%)$ subjects had previous upper limb fracture, two $(0.4 \%)$ subjects had hand osteoarthritis, twelve $(2.3 \%)$ subjects had history of prolonged pain through the last decade, and 265 $(51 \%)$ subjects had a member of the family with RSIs. Only $83(16 \%)$ subjects participated in regular exercises, two hundred eighty-eight (56\%) subjects drink coffee and $21(4 \%)$ subjects wear high heel shoe. Three hundred sixteen $(61.4 \%)$ subjects had to stretch to write on board, and 97 (18.8\%) subjects work with computer. Regarding teaching posture, four hundred fifteen $(80.6 \%)$ subjects had prolonged teaching posture, while100 (9.4\%) had alternated teaching posture (Table 1, Fig. 1).

\section{III- Prevalence of RSIs in Giza secondary schools:}

The prevalence of RSIs in Giza secondary schools was $89.51 \%$ with $95 \%$ CI of $86.56-91.87 \%$. Fifty four (11.49\%) subjects had no RSIs and 461 $(89.51 \%)$ subjects had RSIs pain. There was a significant increase in the prevalence of RSIs $89.51 \%$ compared with non RSIs $11.49 \%$ ( $p=$ $0.0001)$.

In subjects with RSIs, 399 (86.6\%) subjects had the right upper limb affected and 62 (13.4\%) subjects had the left upper limb affected. There was a significant increase in the prevalence of RSIs in the right upper limb $86.6 \%$ compared with that the left upper limb 13.4\% ( $p=0.0001)$ (Table 2, Fig. 2). The shoulder was the commonest site of RSIs pain reported by $35.14 \%$ followed by the neck $31.89 \%$, the wrist by $21.26 \%$, and the elbow by $11.71 \%$.

Table (1): The health status and work characteristics of the study group.

\begin{tabular}{llc}
\hline Health status & \multicolumn{1}{c}{ Yes } & No \\
\hline Chronic disease & $23(4.5 \%)$ & $492(95.5 \%)$ \\
History of trauma & $12(2.3 \%)$ & $503(97.7 \%)$ \\
$\quad$ accident during last 10 years) & & \\
Member of family had RSIs & $265(51 \%)$ & $250(48.5 \%)$ \\
Participation in regular exercise & $83(16 \%)$ & $432(84 \%)$ \\
Drinking coffee & $288(56 \%)$ & $227(44 \%)$ \\
Wearing high heel shoe & $21(4 \%)$ & $494(96 \%)$ \\
& \multicolumn{1}{c}{ Yes } & No \\
Work characteristics & $316(61.4 \%)$ & $199(38.6 \%)$ \\
Stretching to write on board & $97(18.8 \%)$ & $418(81.2 \%)$ \\
Working with Computer & Prolonged & Alternated \\
& $415(80.6 \%)$ & $100(19.4 \%)$ \\
Teaching posture & & \\
\hline
\end{tabular}

Table (2): Difference between RSIs in right and left sides.

\begin{tabular}{rcccc}
\hline Right side & Left side & z-value & $p$-value & Sig. \\
\hline RSIs 399 $(86.6 \%)$ & $62(13.4 \%)$ & 22.2 & 0.0001 & S \\
\hline
\end{tabular}

$p$-value: Probability value. $\quad S$ : Significant.

There was a significant association between age and RSIs $(p=0.02)$. There was a significant increase in the prevalence of RSIs in subjects who are older than 40 years $(92.6 \%)$ compared with subjects who are younger than 40 years $(86.5 \%)$. There was a significant increase in the prevalence of RSIs in females $94.7 \%$ compared with that in males $79.7 \%$ ( $p=0.0001)$. There was no significant association between the teaching experience and RSIs $(p=0.76)$.

There was a significant association between RSIs and working hours per week ( $p=0.0001)$. Additionally, there was a significant increase in the prevalence of RSIs in subjects who work more than $40 \mathrm{hr} /$ week (95.5\%) compared with that in subjects who work less than $40 \mathrm{hr} /$ week (81.9\%). There was no significant association between RSIs and stretching to write on board $(p=0.79)$ or family history of RSIs ( $p=0.09$ ) or coffee intake $(p=0.81)$. However, there was a significant association between RSIs and working with computer $(p=0.01)$. Furthermore, there was a significant increase in the prevalence of RSIs in working with computer user $(91.1 \%)$ compared with that none computer user $(82.5 \%)$. There was a significant association between RSIs and teaching posture $(p=0.006)$. There was a significant increase in the prevalence of RSIs in subjects with prolonged posture $(97 \%)$ compared with that alternated posture $(87.7 \%)$, (Table 3). 
In right side RSIs, the mean \pm SD of right-hand grip strength (affected side) was $28.15 \pm 12.37 \mathrm{~kg}$ and that of the left side was $30.39 \pm 13.17 \mathrm{~kg}$ with the mean difference of $-2.24 \mathrm{~kg}$. There was a significant decrease in right hand grip strength compared with that of the left side $(p=0.0001)$ in rightside RSIs. In left-side RSIs, the mean \pm SD of the right-hand grip strength was $37.63 \pm 12.96 \mathrm{~kg}$ and that of the left side (affected side) was $31.29 \pm 11.45$ $\mathrm{kg}$ with the mean difference of $6.34 \mathrm{~kg}$. There was a significant decrease in left hand grip strength compared with that of the right side $(p=0.0001)$ in left side RSIs. (Table 4, Fig. 3).
In right-side RSIs, the mean \pm SD of right pinch grip strength (affected side) was $11.44 \pm 5.55 \mathrm{~kg}$ and that of the left side was $11.86 \pm 5.33 \mathrm{~kg}$ with the mean difference of $-0.42 \mathrm{~kg}$. There was a significant decrease in right-side pinch grip compared with that of the left side $(p=0.0004)$ in right side RSIs. In left-side RSIs, the mean \pm SD of the right pinch grip strength was $13.13 \pm 5.8 \mathrm{~kg}$ and that of the leftside (affected side) was $10.85 \pm 5.59 \mathrm{~kg}$ with the mean difference of $2.27 \mathrm{~kg}$. There was a significant decrease in left pinch grip strength compared with that of the right side $(p=0.0001)$ in left side RSIs. (Table 5, Fig. 4).

Table (3): The prevalence of RSIs with selected factors.

\begin{tabular}{|c|c|c|c|c|c|}
\hline \multirow{2}{*}{ Factors } & \multicolumn{2}{|c|}{ Prevalence of RSIs } & \multirow{2}{*}{$\chi^{2}$-value } & \multirow{2}{*}{$p$-value } & \multirow{2}{*}{ Sig. } \\
\hline & Yes & No & & & \\
\hline \multicolumn{6}{|l|}{ Age classes: } \\
\hline$<40$ years & $224(86.5 \%)$ & $35(13.5 \%)$ & 5.09 & 0.02 & S \\
\hline$>40$ years & $237(92.6 \%)$ & $19(7.4 \%)$ & & & \\
\hline \multicolumn{6}{|l|}{ Gender: } \\
\hline Females & $320(94.7 \%)$ & $18(5.3 \%)$ & 27.89 & 0.0001 & $S$ \\
\hline Males & $141(79.7 \%)$ & $36(20.3 \%)$ & & & \\
\hline \multicolumn{6}{|l|}{ Teaching experience: } \\
\hline$<16$ years & $232(89.9 \%)$ & $26(10.1 \%)$ & 0.09 & 0.76 & NS \\
\hline$>16$ years & $229(89.1 \%)$ & $28(10.9 \%)$ & & & \\
\hline \multicolumn{6}{|l|}{ working hours per week: } \\
\hline$>40 \mathrm{~h} /$ week & $275(95.5 \%)$ & $13(4.5 \%)$ & 24.82 & 0.0001 & S \\
\hline$<40 \mathrm{~h} /$ week & $186(81.9 \%)$ & $41(18.1 \%)$ & & & \\
\hline Stretching to write on board & $282(89.2 \%)$ & $34(10.8 \%)$ & 0.06 & 0.79 & NS \\
\hline No stretch & $179(89.9 \%)$ & $20(10.8 \%)$ & & & \\
\hline \multicolumn{6}{|l|}{ Family history of RSIs: } \\
\hline Positive & $243(91.7 \%)$ & $22(8.3 \%)$ & 2.77 & 0.09 & NS \\
\hline Negative & $218(87.2 \%)$ & $32(12.8 \%)$ & & & \\
\hline Drinking coffee & $257(89.2 \%)$ & $23(10.1 \%)$ & 0.05 & 0.81 & NS \\
\hline No coffee intake & $204(89.9 \%)$ & & & & \\
\hline \multicolumn{6}{|l|}{ Work with computer: } \\
\hline Computer user & $381(91.1 \%)$ & $37(8.9 \%)$ & 6.31 & 0.01 & $\mathrm{~S}$ \\
\hline None computer user & $80(82.5 \%)$ & $17(17.5 \%)$ & & & \\
\hline \multicolumn{6}{|l|}{ Teaching posture: } \\
\hline Prolonged & $97(97 \%)$ & $3(3 \%)$ & 7.4 & 0.006 & S \\
\hline Alternated & $364(87.7 \%)$ & $51(12.3 \%)$ & & & \\
\hline
\end{tabular}

Table (4): $t$-test for difference between the right and left Handgrip strength in the side of RSIs.

\begin{tabular}{lcccccc}
\hline Side of RSIs & $\begin{array}{c}\text { Rt. Handgrip } \\
(\mathrm{kg})\end{array}$ & $\begin{array}{c}\text { Lt. Handgrip } \\
(\mathrm{kg})\end{array}$ & MD (95\%CI) & $t$-value & $p$-value & Sig. \\
\hline Rt side $(\mathrm{n}=399)$ & $28.15 \pm 12.37$ & $30.39 \pm 13.17$ & $-2.24(-2.95,-1.52)$ & -6.13 & 0.0001 & $\mathrm{~S}$ \\
Lt side $(\mathrm{n}=62)$ & $37.63 \pm 12.96$ & $31.29 \pm 11.45$ & $6.34(4.65,8.02)$ & 7.52 & 0.0001 & $\mathrm{~S}$ \\
\hline$t$-value: Unpaired $t$-value. $\quad p$-value: Probability value. & MD: Mean difference. & \multicolumn{2}{c}{ S: Significant. }
\end{tabular}


Table (5): $t$-test for difference between the right and left pinch grip strength in the side of RSIs.

\begin{tabular}{lcccccc}
\hline Side of RSIs & $\begin{array}{c}\text { Rt Pinch grip } \\
(\mathrm{kg})\end{array}$ & $\begin{array}{c}\text { Lt Pinch grip } \\
(\mathrm{kg})\end{array}$ & MD $(95 \% \mathrm{CI})$ & $t$-value & $p$-value & Sig. \\
\hline Rt side $(\mathrm{n}=399)$ & $11.44 \pm 5.55$ & $11.86 \pm 5.33$ & $-0.42(-0.66,-0.19)$ & -3.54 & 0.0004 & $\mathrm{~S}$ \\
Lt side $(\mathrm{n}=62)$ & $13.13 \pm 5.8$ & $10.85 \pm 5.59$ & $2.27(1.55,3.0)$ & 6.29 & 0.0001 & $\mathrm{~S}$ \\
\hline -value: Unpaired $t$-value. $\quad p$-value: Probability value. & MD: Mean difference. & \multicolumn{2}{c}{ S: Significant. }
\end{tabular}

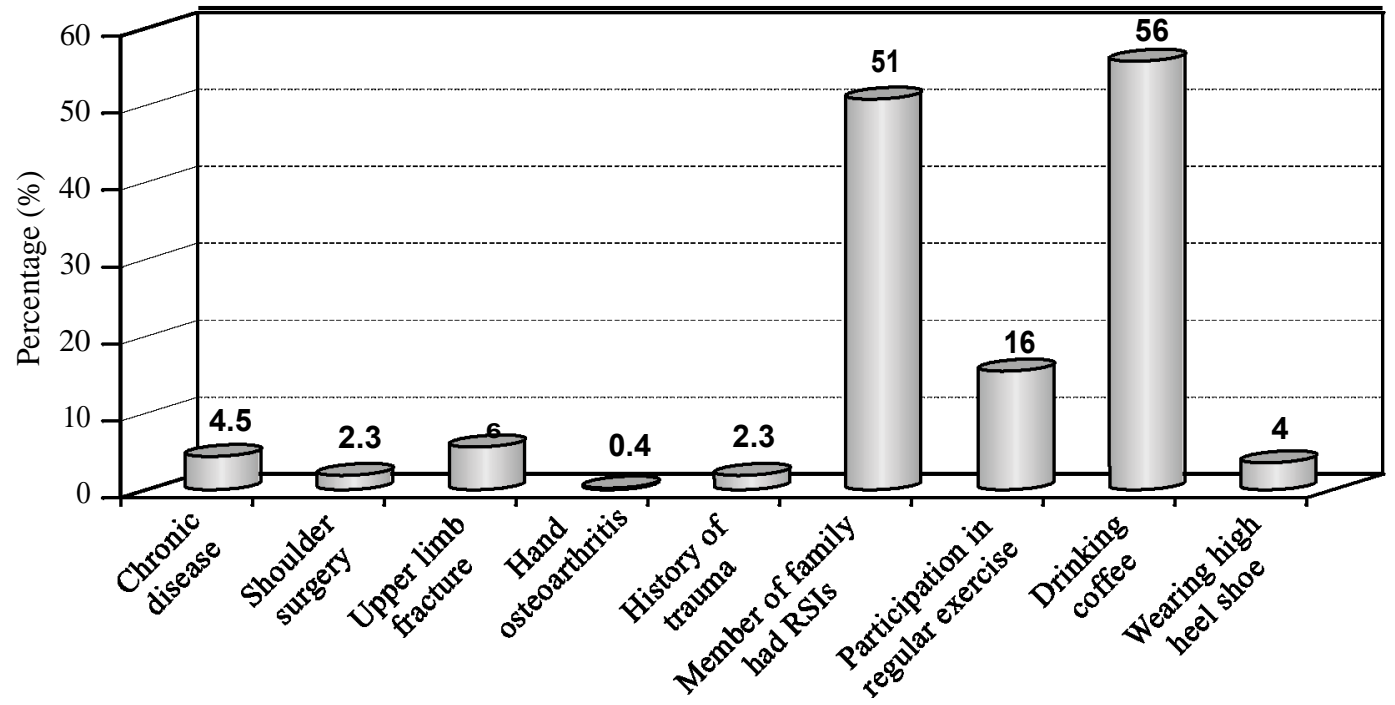

Fig. (1): Health Status of the study group.

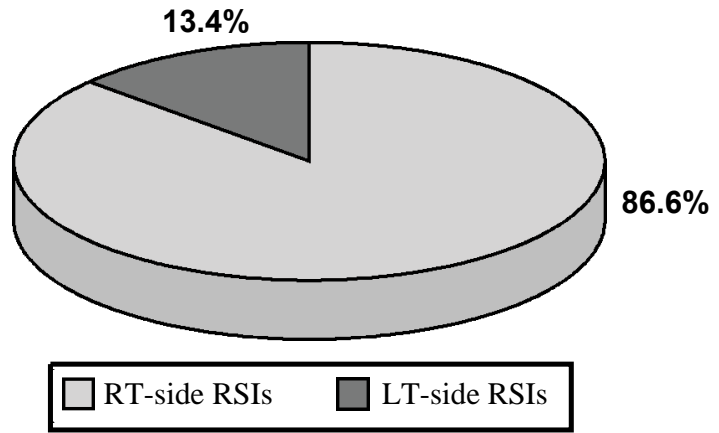

Fig. (2): Prevalence of RSIs of right and left sides.

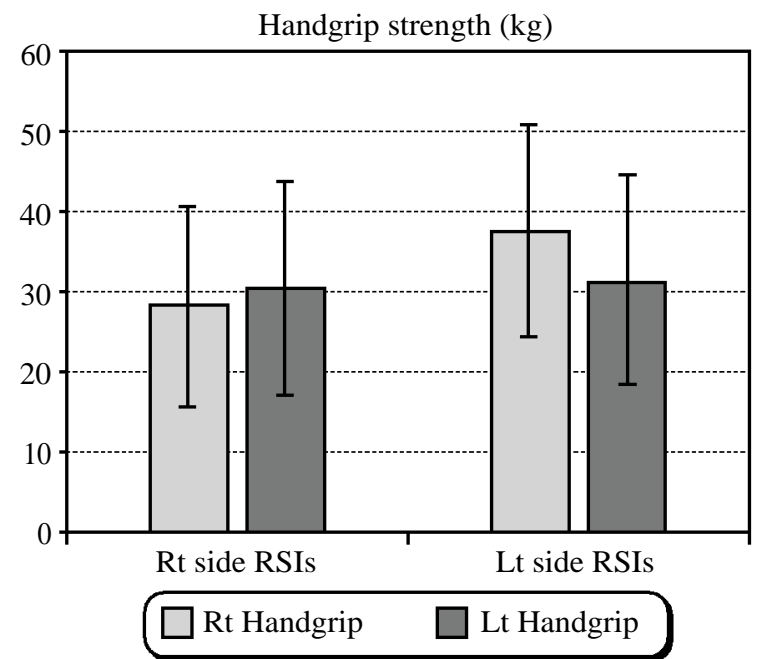

Fig. (3): Effect of RSIs side on right and left hand grip strength.

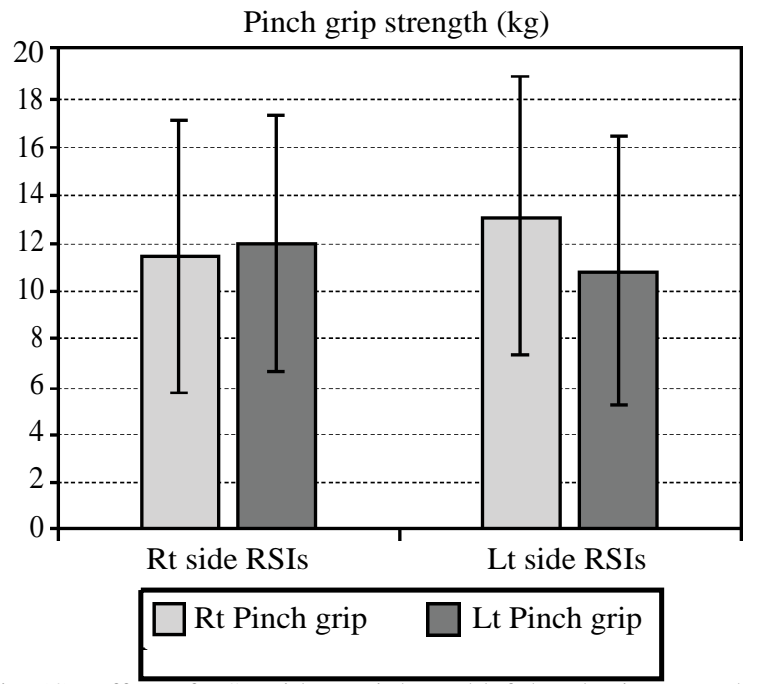

Fig. (4): Effect of RSIs side on right and left hand grip strength.

\section{Discussion}

School teachers represent an occupational group, in which the prevalence of RSIs, in various body sites, seems to be elevated [6]. The result of the current study revealed that there is high prevalence of RSIs found among teachers in Giza schools (89.51\%), supported from some previous reports regarding RSIs among teachers in Ethiopia, Thailand, Hong Kong, India, Kuala Lumpur, Nigeria and in Malaysia [1,6,12-16]. Nevertheless, the 
prevalence of this research is higher than the studies carried out in China, Saudi Arabia, Japan and Brazil, where the prevalence ranged from $31.6 \%$ to $60 \%$ [17-20]. This difference that was recorded in prevalence rate of RSIs could be as a result of the difference in the educational systems, study design, the facilities available for the teachers at their schools or social, cultural, and economic differences between Egypt and other nations.

The highest prevalence of RSIs was at the area of the shoulder $(35.14 \%)$ which was in line with that in Hong Kong, with prevalence $(69.3 \%)$ [12], China (73.4\%) [21], India (33.12\%) [13], and in Nigeria (62.3\%) [15]. There was a significant increase in the prevalence of RSIs in teachers of more than 40 years old compared with subjects of less than 40 years. The reasons might be the consequence of aging, age-related degenerative changes, turning down of tissue healing, lessening of cartilage, and increasing suffering to neck and shoulder structures due to workload. This result is in line with the strides conducted in Botswana, Ethiopia and in Malaysia [6,16].

There was a significant increase in the prevalence of RSIs in subjects with more than forty working hours per week compared with that in subjects with less than forty working hours per week which were supported by some previous studies in Thailand, Hong Kong and in Malaysia $[1,12,16]$. There was a significant increase in the prevalence of RSIs in females contrasted with that in males, this is matched with the studies of university academic staff in Hong Kong, China, India, Kuala Lumpur, and in Nigeria [13-15,21,22]. The elevated hazard of developing RSIs after teaching in females could be explained by many factors as they were more likely suffering emotional exhaustion compared with males among teachers [23] Also, females have a lower pain threshold than males, where the pressure pain threshold increases with muscle strength [24], and the muscle strength in the upper limb for males is 1.2-1.7 times those in females. Consequently, females could have a lower pain threshold than males [22].

There was no association between a teaching experience and RSIs in the current study. However, in Hong Kong, teachers with teaching experience of less than 5 years got the highest life-long prevalence of RSIs [12]. This could be due to the sample size; in Hong Kong the sample size was one hundred teachers from secondary schools collected by simple one stage cluster sampling method [12], but in our study; Sample size were five hundred and fifteen randomly selection.
There was no significant association between RSIs and stretching to write on board which was similar to that in Hong Kong [12]. In the current study, there was no significant association between RSIs and family history of RSIs, however, in that of Thailand, family members had two times higher risk developing RSIs compared to the healthy family [1]. This could be due to the sampling selection method; in Thailand were collected by simple one stage cluster sampling method [1], but in our study; Samples were randomly selected.

Also there was no significant association between RSIs and coffee intake. There was a significant increase in the prevalence of RSIs in working with computer users compared to that of noncomputer users which was confirmed with the results of previous studies in Hong Kong and Nigeria [15,22]. Working with a poking chin position during computer processing would induce a significant load on the subsequent neck muscle leading to muscle weakness. This would boost loading on non-contractile composition and posterior cervical structures causing RSIs [4].

In our study, there was a significant increase in the prevalence of RSIs in teachers with prolonged posture compared with that with alternated posture. This was matched with the studies in Thailand [1], Ethiopia [6], and in Hong Kong [4] because the awkward position by persistent muscle stretching, mainly the overhead position, induced neck and upper limb disorders in teachers. Repetitive strain injuries had a negative impact on hand and pinch grip strengths of governmental secondary school teachers in Giza. Hand and pinch grip strength decrease in the side of RSIs compared with the side of non RSIs. These findings were matched with the studies in USA [25], Japan [26], and in Turkey [27]

\section{Conclusion:}

This study showed that there is a high significant prevalence of RSIs in the upper extremities among teachers in government secondary schools in Giza. Also, there is a high significant prevalence of RSIs in right side compared with that of the left side. Furthermore, repetitive strain injuries had a negative impact on hand and pinch grip strengths of governmental secondary school teachers in Giza.

\section{Acknowledgements:}

The authors thank all patients who participated in this study.

\section{Funding:}

No financial support was received. Funding No financial support was received. 


\section{Conflict of interest:}

The authors declare no conflicts of interest.

\section{References}

1- SUNISA C. and PORNNAPA S.: Risk factors for repetitive strain injuries among school teachers in Thailand. Work, 41 (1): 2510-2515, 2012.

2- MAGUIRE M. and O'CONNEL T.: Health retirement of schoolteacher in the republic of Ireland. Occupational Medicine, 57 (3): 191-193, 2007.

3- BARBARA O'NEIL, O'NEIL, FORSYTHE, MICHAEL E., STANISH and WILLIAM D.: Chronic occupational repetitive strain injury. Canadian Family Physician, 47 (2): 311-316, 2001

4- CHIU T.T. and LAM P.K.: The prevalence of and risk factors for neck pain and upper limb pain among secondary school teachers in Hong Kong. J. Occup. Rehabil, 17 (1): 19-32, 2007.

5- PATIENCE E. and DEREK S.: A systematic review of musculoskeletal disorders among school teachers. BMC Musculoskeletal Disorders, 12 (1): 1-11, 2011.

6- MELAKU H., TEMESGEN, BELAY G.J., GELAW A.Y., JANAKIRAMAN B. and ANIMUT Y.: Burden of shoulder and/neck pain among school teachers in Ethiopia. BMC Musculoskeletal Disorders, 20 (1): 1-9, 2019.

7- FAYEZ E. and EMAN S.: The correlation between neck pain and hand grip strength of dentists. Occupational Medicine \& Health Affairs, 185 (2): 2-5, 2014.

8- SOLOVIEVA S., VEHMAS T., RIIHIMÄKI H., LUOMA $K$. and LEINO-ARJAS P.: Hand use and patterns of joint involvement in osteoarthritis. A comparison of female dentists and teachers. Rheumatology, 44 (4): 521-528, 2005.

9- MATHIOWETZ V.: Comparison of Rolyan and Jamar dynamometers for measuring grip strength. Occupational Therapy International, 9 (3): 201-209, 2002.

10-ROBERTS H.C., ROBERTS H.C., DENISON H.J., MARTIN H.J., PATEL H.P., SYDDALL H., et al.: A review of the measurement of grip strength in clinical and epidemiological studies: Towards a standardised approach. Age and Ageing, 40 (4): 423-429, 2011.

11- DEBRA L., ANDREW KRATT and BIX L.: Interrater reliability of students using hand and pinch dynamometers. American Journal of Occupational Therapy, 63 (2): 193 197, 2009.

12- THOMAS C. and PEGGO K.W.: The prevalence of and risk factors for neck pain and upper limb pain among secondary school teachers in Hong Kong. Journal of Occupational Rehabilitation, 17 (1): 19-32, 2007.

13- VAGHELA N.P., NIRAV P., PAREKH and SANKET K Prevalence of the musculoskeletal disorder among school teachers. National Journal of Physiology, Pharmacy and Pharmacology, 8 (2): 197-201, 2018.

14- NG, YI MING, VOO P. and MAAKIP I.: Psychosocial factors, depression, and musculoskeletal disorders among teachers. BMC Public Health, 19 (1): 1-10, 2019.
15- OJUKWU C.P., ANYANWU G.E., EZE B., CHUKWU S.C., ONUCHUKWU C.L. and ANEKWU E.M.: Prevalence, pattern and correlates of work-related musculoskeletal disorders among school teachers in Enugu, Nigeria. International Journal of Occupational Safety and Ergonomics, 27 (1): 267-277, 2018.

16- ALIAS A.N., AYUNI NABILAH, KARUPPIAH, KARMEGAM, VIVIEN, PERUMAL and VELU: Prevalence of musculoskeletal disorders (MSDS) among primary school female teachers in Terengganu, Malaysia. International Journal of Industrial Ergonomics, 1 (77): 102957. https://doi.org/10.1016/j.ergon.2020.102957, 2020.

17- YUE P., PENGYING, LIU F. and LI L.: Neck/shoulder pain and low back pain among school teachers in China, prevalence and risk factors. BMC Public Health, 12 (1): $1-8,2012$.

18- ZAMRI E.N., MOY F.M. and HOE V.C.: Association of psychological distress and work psychosocial factors with self-reported musculoskeletal pain among secondary school teachers in Malaysia. PloS One, Feb. 24, 12 (2): e0172195, 2017.

19- ONO Y., IMAEDA T., SHIMAOKA M., HIRUTA S., HATTORI Y., ANDO S., et al.: Associations of length of employment and working conditions with neck, shoulder and arm pain among nursery school teachers. Industrial Health, 40 (2): 149-158, 2002.

20- ALBANITA GOMES da COSTA de, CEBALLOS, SANTOS, GUSTAVO BARRETO: Factors associated with musculoskeletal pain among teachers, Socio-demographics aspects, general health and well-being at work. Revista Brasileira de Epidemiologia, 18: 702-15, 2015.

21- CHONG E.Y. and CHAN A.H.: Subjective health complaints of teachers from primary and secondary schools in Hong Kong. International journal of occupational safety and ergonomics, 16 (1): 23-39, 2010.

22- CHIU T.T., KU W.Y., LEE M.H., SUM W.K., WAN M.P., WONG C.Y., et al.: A study on the prevalence of and risk factors for neck pain among university academic staff in Hong Kong. Journal of Occupational Rehabilitation, 12 (2): 77-91, 2002.

23- CHANG-JIANG L., GUO-XIANG W. and XIN-CHUN W.: Analysis of Occupational Burnout of High School Teachers [J]. Journal of Shenyang Normal University Social Sciences Edition, 28 (6): 118-121, 2004.

24- TORGEN M. and SWERUP C.: Individual factors and physical work load in relation to sensory thresholds in a middleaged general population sample. European Journal of Applied Physiology, 86 (5): 418-427, 2002.

25- GRANT K.A., HABES D.J. and TEPPER A.L.: Work activities and musculoskeletal complaints among preschool workers. Appl. Ergon., 26 (6): 405-410, 1995.

26- TSUBOI H., TAKEUCHI K., WATANABE M., HORI R. and KOBAYASHI F.: Psychosocial factors related to low back pain among school personnel in Nagoya, Japan. Ind. Health, 40 (3): 266-271, 2002.

27- KORKMAZ N.C., CAVLAK U. and TELCI E.A.: Musculoskeletal pain, associated risk factors and coping strategies in school teachers. Scientific Research and Essays, 6 (3): 649-657, 2011. 


\section{مدى انتشار إصابات الاجهاد المتكررة فى الأطراف العليا

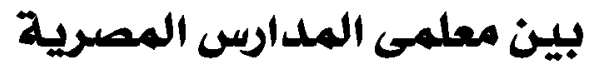

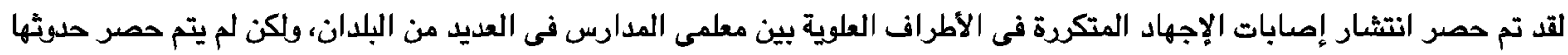

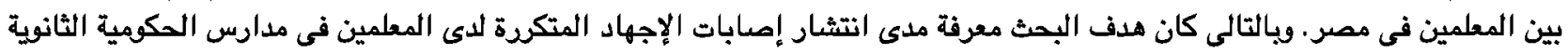

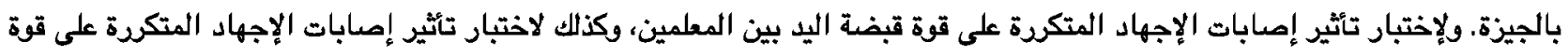
قبضة القرصة بين المعلمين.

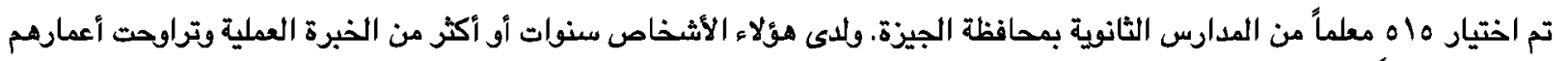

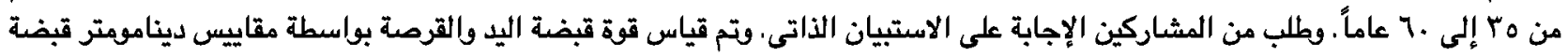
اليد والقرصة.

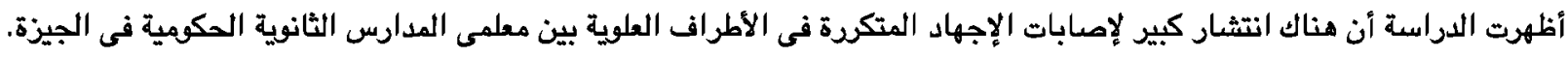

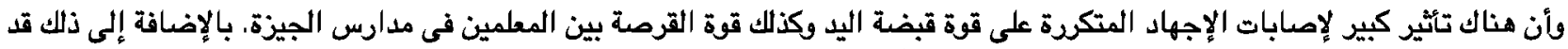

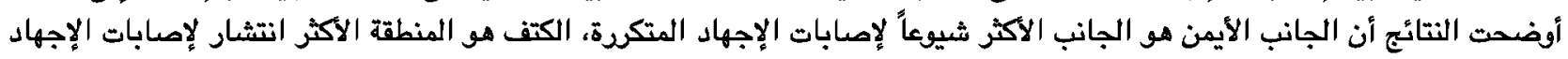

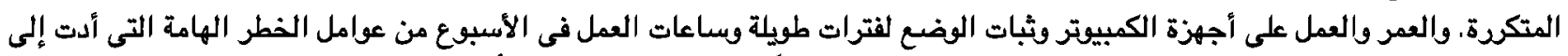

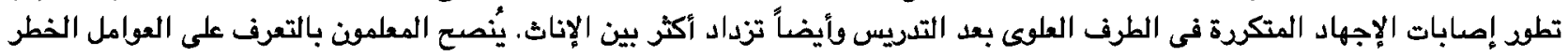
المهنية وتقليلها، إن أمكن، التقليل فرصة الإصابة بألم الرقبة وألم الأطراف العلوفية. 